\title{
Observed characteristics of sudden commencement absorption
}

\author{
S.E. Ritchie ${ }^{\mathrm{a}, \mathrm{b}, *}, \mathrm{~F}$. Honary ${ }^{\mathrm{b}}$

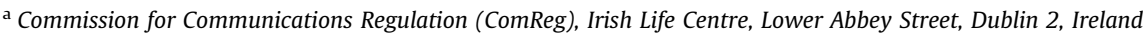 \\ ${ }^{\mathrm{b}}$ Department of Communication Systems, University of Lancaster, Lancaster LA1 4W4, UK
}

\section{A R T I C L E I N F O}

\section{Article history:}

Received 7 June 2008

Received in revised form

12 November 2008

Accepted 21 November 2008

Available online 16 December 2008

\section{Keywords:}

Sudden commencement absorption

Storm sudden commencement

Riometer

IMF

\begin{abstract}
A B S T R A C T
Ionospheric absorption at high latitudes that occurs coincidently with storm sudden commencements (SSC) is categorised as sudden commencement absorption (SCA). Having discounted any solar activity effects on the measurement of SCA this paper describes, for the first time, the basic characteristics of SCA measured over half a solar cycle.

It is revealed that the measurement of SCA is not affected by Solar activity, the local time of occurrence of the SSC or the direction of $B_{z}$ immediately before or after the SSC event. We also show that the median value of expected SCA is best predicted by the step change in IMF magnetic field coincident with the SSC event. This strong correlation between the median value of SCA and the IMF magnitude that occurred during the shock has been formulated to aid propagation prediction.
\end{abstract}

(c) 2008 Elsevier Ltd. All rights reserved.

\section{Introduction}

Sudden enhancements in the solar wind dynamic pressure are known to compress the magnetosphere and enhance the magnetopause current (Kaufmann and Konradi, 1969), as well as the tail currents (Russell et al., 1994). Zesta et al. (2000) noted in a study of the 10 January 1977 disturbance that the response of the magnetosphere to a pressure front was practically instantaneous, global and directly driven by the propagation of the solar wind density enhancement region through the magnetosphere. The disturbance is transmitted throughout the magnetosphere in the form of hydromagnetic waves and has been observed both at satellite altitudes and on the ground as a sudden increase or decrease in the geomagnetic field strength. Corresponding to the changes in geomagnetic field strength are changes in the magnetic field geometry, the electric field configuration as well as changes in thermal and energetic particle distributions.

\subsection{Storm sudden commencements}

An interplanetary disturbance in the solar wind such as shock waves and dynamic pressure pulses (Wilken et al., 1982; Tsurutani et al., 1995; Takeuchi et al., 2002a), when impinging on the Earth's magnetosphere, compresses it and increases the magnetopause current. This leads to a change in the low-latitude ground-based

\footnotetext{
* Corresponding author at: Commission for Communications Regulation (ComReg), Irish Life Centre, Lower Abbey Street, Dublin 2, Ireland. Tel.: +35318049619.

E-mail addresses: samuel.ritchie@comreg.ie (S.E. Ritchie), f.honary@lancaster.ac.uk (F. Honary).
}

geomagnetic field intensity, lasting typically for some tens of minutes. These signatures in the geomagnetic H-field, seen suddenly and simultaneously at ground magnetic observatories (Rastogi et al., 2001) are called Storm Sudden Commencements (SSC) or Sudden Impulses (SI), depending whether a magnetospheric storm is initiated or not.

The International Association of Geomagnetism and Aeronomy collate widespread observatory magnetometer data in order to compile a list of agreed SSC events (IAGA). Burlaga and Ogilvie (1969), Gosling et al. (1967) and Ogilvie et al. (1968) have shown the good correlation between impulsive changes in solar wind parameters and SSC signatures in the magnetosphere or on the ground. The same researchers as well as Hirshberg et al. (1970) demonstrated that SCC events are caused by hydromagnetic shock waves and tangential discontinuities in the solar wind interacting with the magnetosphere and a hydromagnetic description of SSC events has been given by Wilson and Sugiura (1961) and Tamao (1964b, 1975). The SSC generated by these hydromagnetic shock waves transform the magnetosphere into a new compressed steady-state configuration, which is in balance with the increased solar wind pressure (Wilken et al., 1982, 1986; Tamao, 1964, 1975).

\subsection{Sudden commencement absorption}

Previous studies have shown that on occasion, brief ionospheric absorption events occur promptly with the sudden commencements of geomagnetic storms. Confirmed as particle precipitation events, observed as ionospheric absorption occurring simultaneously with the SSC (Ranta and Ranta, 1990), these 
sudden commencement absorption (SCA) events occur most often at auroral latitudes (Ortner et al., 1962).

The first record of an absorption event of this kind appears to be the one described by Brown et al. (1961) and was associated with the SSC of 27 June 1960 and the assumption from this and other studies is that the ionisation in the lower ionosphere that occurs at the time of an SSC is due to X-rays, presumably originating at a greater height from electrons entering the upper atmosphere. The fact that SCA effects have been found to be concentrated in the auroral zone clearly implies that the ionising electrons are precipitating into the earth's atmosphere along the geomagnetic field lines.

Ortner et al. (1962) noted that when taking reading on a colocated vertical and oblique riometer (Relative Ionospheric Opacity Meter using Extra Terrestrial Electromagnetic Radiation), that most SSC absorption events were strongest on the oblique riometer than on the vertical riometer. This is consistent with the concept of a uniform absorbing layer, increasing absorption being due to the obliquity factor for the oblique riometer.

\subsection{Energisation and source of SCA particles}

Precipitation into the high latitude auroral zones is predominantly through scattering of energetic particles from closed field lines, which are lost into the denser atmosphere. The scattering process is usually due to the growth of wave particle interactions, feeding and extracting energy from the trapped, mirroring particles and altering the pitch angle distribution (Kavanagh et al., 2002).

Indeed, wave-induced particle precipitation is often assumed to be the cause of SCA (Leinbach et al., 1970; Perona, 1972), implying that changes in wave activity are triggered by the SSC throughout a large portion of the inner magnetosphere. Since the adiabatic changes in particle trajectories can only increase the pitch angle, adiabatic effects alone cannot increase the particle flux within the loss cone and thus cannot account for all the absorption seen. With the assumed absence of other scattering mechanisms during the initial perturbation, the increase absorption seen must therefore result from waveinduced precipitation (Gail et al., 1990).

In an examination of impulsive bursts of cosmic noise absorption observed at the time of sudden commencement Osepian and Kirkwood (2004) related the occurrence and associated absorption values with the perturbation in magnetic field strength in the equatorial magnetosphere and explained the results quantitatively in the framework of whistler cyclotron instability theory.

Kikuchi and Yamagishi (1989) present compelling results that indicate that the energetic electrons associated with an SSC originate in the trapped radiation belt. Using a scanning beam riometer at Syowa Station (Antarctica, $L=6.1$ ) the authors observed a distinct differences in the latitudinal features of energetic electron precipitation and the time delay of precipitation associated with a SSC, and precipitation associated with substorms. The result strongly suggests that the SCA-associated energetic electrons originate in the trapped radiation belt within the plasmasphere where the closed field lines are limited in latitude. Those particles precipitating during substorms must come from outside the plasmasphere, most likely from the plasmasheet where access to higher latitudes is possible.

In order to find the best predictor of SCA based on one or more solar wind parameters, a statistical study of SCA covering 6 years of data has been carried out and presented in this paper.

\section{Data}

From the IAGA list, SSC events spread across the years 2000-2006 were selected for analysis. This period encompasses more than half a solar cycle, from the sunspot maximum in 2000 to the near sunspot minimum in 2006 and allows any dependency on solar activity to be evaluated. During this period a total of 201 SSC events occurred of which 26 were categorised in the IAGA list as possible SI events by one or more participating observatories. To ensure only unambiguous SSC events were examined, these 26 events were discounted, leaving 175 events that form the basis of the findings in this paper.

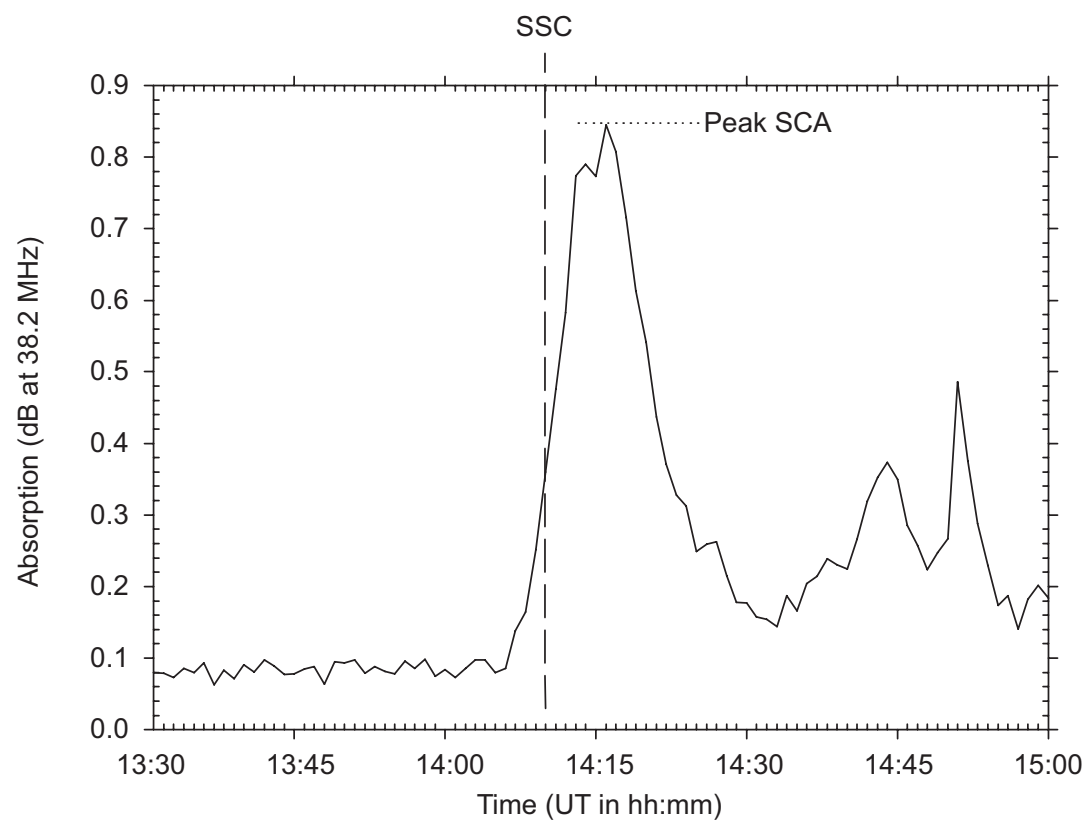

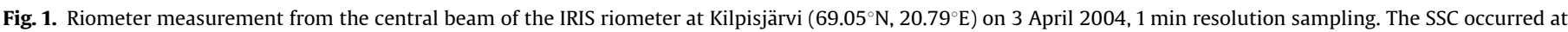
14:10 UT, which is indicated by the long-dashed line. The peak SCA measured in this example is indicated by the dotted line. 


\subsection{Riometer data}

The riometer is a simple instrument developed in the 1950s (e.g. Little and Leinbach, 1959) that makes medium-scale measurements of ionospheric absorption of cosmic noise at a frequency in the order of $30 \mathrm{MHz}$. Operation is passive and the background cosmic radio noise from the sky is constantly monitored. By comparing the background cosmic radio noise from the sky against the received signal for an undisturbed day it is possible to determine the variation of ionospheric absorption.

In essence a riometer observes temporal variations in ionisation in the $\mathrm{D}$ and $\mathrm{E}$ regions caused by charged particle precipitation (Hargreaves, 1969), by electrons in the energy range of $\sim 10-100 \mathrm{keV}$ (Wilson and Stoker, 2002). For each of the 175 SSC events examined, data from the IRIS riometer at Kilpisjärvi $\left(69.1^{\circ} \mathrm{N}, 20.8^{\circ} \mathrm{E}, L=6.06\right)$ was used to measure the peak absorption resulting from particle precipitation caused by SSC shocks.

An example of such an absorption signature, from the 3 April 2004 SSC event, which occurred at 14:10 UT, is shown in Fig. 1. Before the SSC the absorption was negligible. At the start of the SSC the absorption increases within 5 min to $0.8 \mathrm{~dB}$, peaking at
$0.85 \mathrm{~dB}, 10 \mathrm{~min}$ after the SSC event commences. Fifteen minutes after the peak the absorption falls to less than $0.2 \mathrm{~dB}$ with some variability thereafter due to subsequent magnetospheric activity.

Excluded from the dataset, by visual examination of each riometer record, are cases where absorption cannot be clearly attributed to the corresponding SSC events or where observations occurred against a background of solar proton precipitation. This ensures that absorption phenomena other than SCA is excluded from the dataset.

\subsection{Solar wind and IMF data}

Solar wind and IMF data for this study was sourced from measurements taken by the ACE spacecraft. See Stone et al. (1998) for details of the satellite and instrumentation. Fig. 2 is a typical example of the data collected for each SSC event. This particular event occurring at 10:52 UT corresponding to a SSC observed at the Earth's surface at 11:37 UT. The window of measurement is marked between long dashed lines.

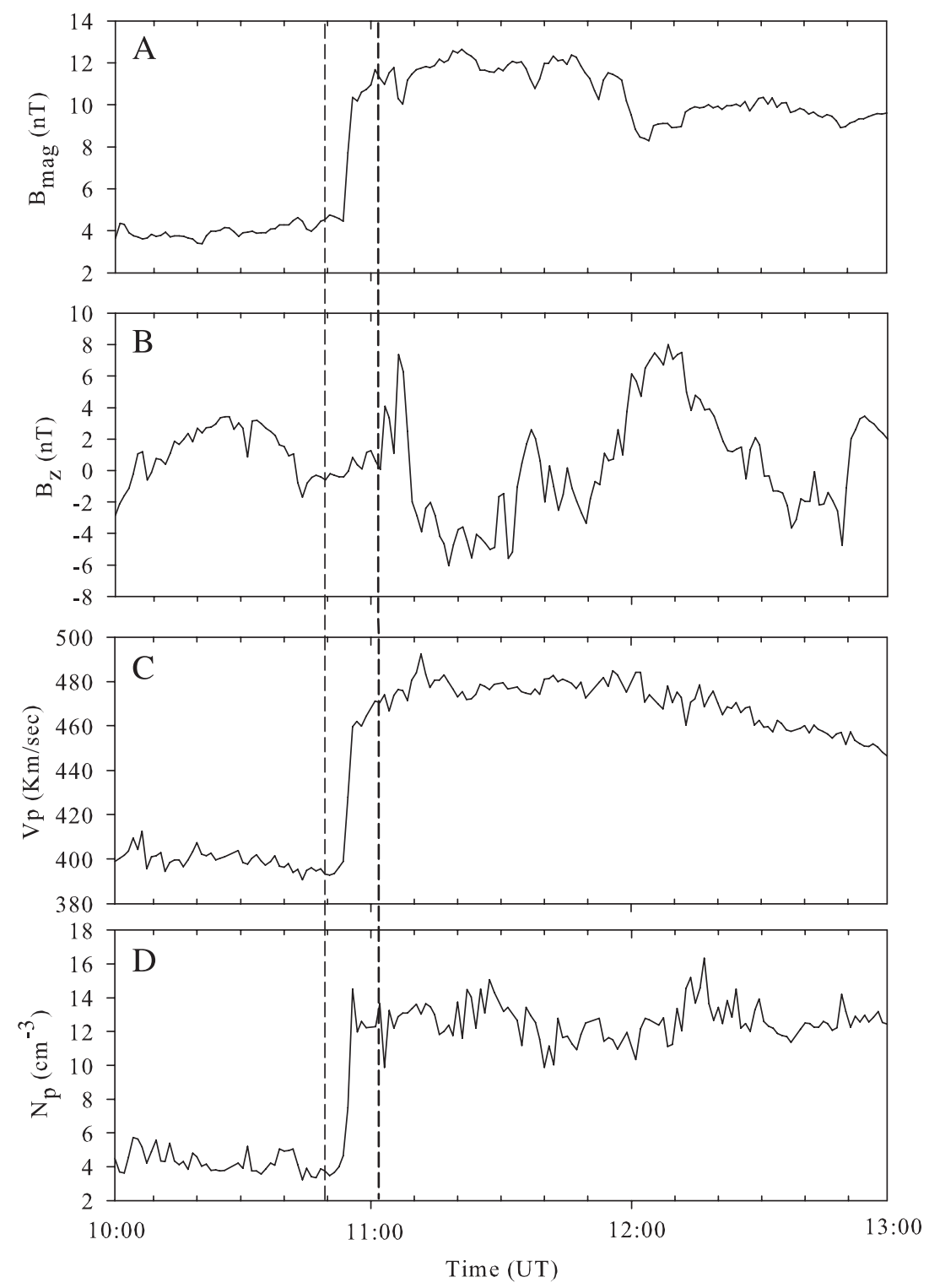

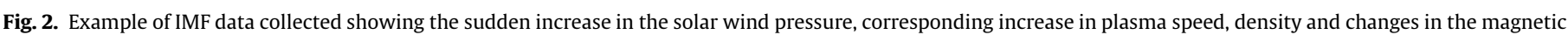
components. Data from the 23 March 2002, 64 s averages used. 
Fig. 2A captures the magnitude of the IMF carried by the solar wind. Before the shock the solar wind was quiet for more than $12 \mathrm{~h}$. Following the shock the amplitude more than doubles and remains at this elevated level for at least another $12 \mathrm{~h}$.

Fig. 2B indicates the magnitude and hence the direction of the $B_{z}$ component of the IMF. $B_{z}$ oscillates between slightly positive and slightly negative before and during the window of measurement. After which $B_{z}$ undergoes first a stronger positive (movement north) then negative (movement south) before continuing with larger oscillations for a number of hours.

Fig. $2 \mathrm{C}$ captures the solar wind proton velocity $\left(V_{p}\right)$, which is fairly steady around $400 \mathrm{~km} / \mathrm{s}$ for $12 \mathrm{~h}$ before the shock. Following the shock the velocity increases to nearly $480 \mathrm{~km} / \mathrm{s}$ before slowly tailing off over the next $8 \mathrm{~h}$.

Table 1

Description of solar wind data gathered for each SSC event.

\begin{tabular}{lll}
\hline & Description & $\begin{array}{l}\text { Value from } \\
\text { Fig. } 2\end{array}$ \\
\hline$\Delta B$ & The change in IMF magnitude (Fig. 2A) & $6 \mathrm{nT}$ \\
$B_{z}$ & The change in direction of the $B_{z,}$ Component (Fig. 2B) & South to North \\
$\Delta V_{p}$ & The change in proton velocity (Fig. 2C) & $75 \mathrm{~km} \mathrm{~s}^{-1}$ \\
$\Delta N_{p}$ & The change in proton density (Fig. 2D) & $10.5 \mathrm{~cm}^{-3}$ \\
$P_{R a m}$ & The change in Ram pressure & $4.2 \mathrm{nPa}$ \\
$\Delta_{R} B$ & The relative change in IMF magnitude & 0.18 \\
$\Delta_{R} V_{p}$ & The relative change in proton velocity & 2.63 \\
$\Delta_{R} P_{\text {Ram }}$ & The relative change in ram pressure & 4.03 \\
\hline
\end{tabular}

a Ram pressure is also known as dynamic pressure and is a function of solar wind speed and density. The recommended formula when using ACE data is (SEC 07):

\section{$P=1.6726 \times 10^{-6} N_{p} V_{p}^{2}(\mathrm{nPa})$}

where pressure $P$ is in $\mathrm{nPa}, N_{p}$ is the density (particles $\mathrm{cm}^{-3}$ ) and $V_{p}$ is the velocity $\left(\mathrm{km} \mathrm{s}^{-1}\right)$ of the solar wind.

$\mathrm{b}$ The concept of relative change can be used to normalise any parameter by reflecting the relative change in the parameter and not the absolute value of the change. It is calculated as follows, using pressure as an example:

$\frac{\text { Change in pressure }}{\text { Initial pressure }}=\frac{\Delta P[\mathrm{nPa}]}{P_{i}[\mathrm{nPa}]}$

$$
=\text { unitless relative change in solar wind pressure }
$$

Fig. 2D shows the solar wind proton density $\left(N_{p}\right)$, which is steady below $5 \mathrm{~cm}^{-3}$ for $12 \mathrm{~h}$ preceding the shock after which it increases to a peak of $14 \mathrm{~cm}^{-3}$ where it remains for at least $6 \mathrm{~h}$.

Using the event shown in Fig. 2 as an example, the data in Table 1 was gathered or calculated for each of the 175 SSC events.

\section{Data analysis}

\subsection{Effect of solar activity on SCA}

As the data spans more than half a solar cycle it can be used to determine if solar activity influences the data set. This was done by evaluating the link between SCA and the change in IMF magnitude against solar activity as reflected by the value of the relevant monthly sunspot number.

Fig. 3 (top panel) shows a general spread of low, medium and high values of SCA at all levels of sunspot activity. Fig. 3 (bottom panel) shows a similar pattern in $\Delta B$ (the change in IMF magnitude) at all levels of sunspot activity. It is concluded that there is no causal link between SCA and sunspot number or between IMF magnitude and SCA, other than in the frequency of occurrence of SSC events.

\subsection{Basic characterisation of SCA}

An examination of the basic statistics of all SCA measured is presented to give some idea of the typical SCA levels that can be expected.

Fig. 4 is a graph of SCA measured at each SSC event, sorted left to right by ascending SCA amplitude. A logarithmic vertical axis is used in this graph in order to reveal the range of SCA values measured. The following SCA statistics are revealed in the database:

- Maximum SCA value measured-13.8 dB

- Mean of SCA values calculated-0.84 dB

- Median of SCA values calculated-0.29 dB

- Mode SCA value observed-0.25 dB

- Standard deviation of SCA calculated-1.47 dB
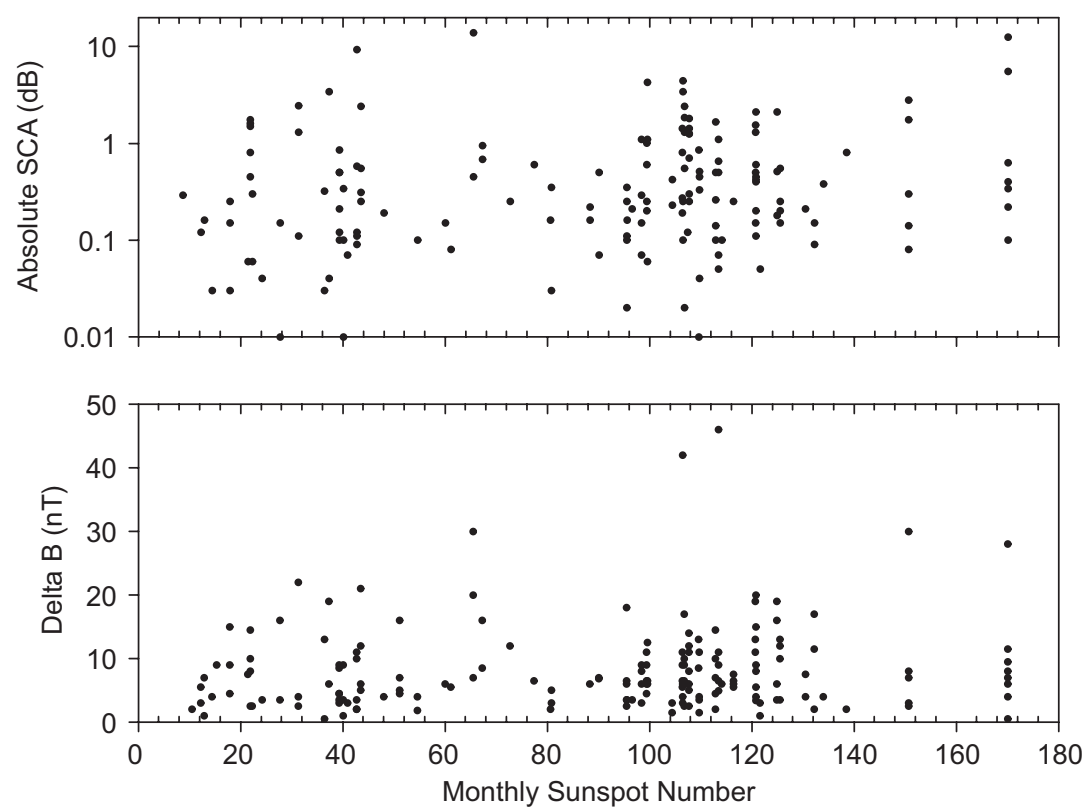

Fig. 3. Scatter plot of the absolute values of SCA vs. monthly sunspot number (top panel) and change in IMF strength (bottom panel). 


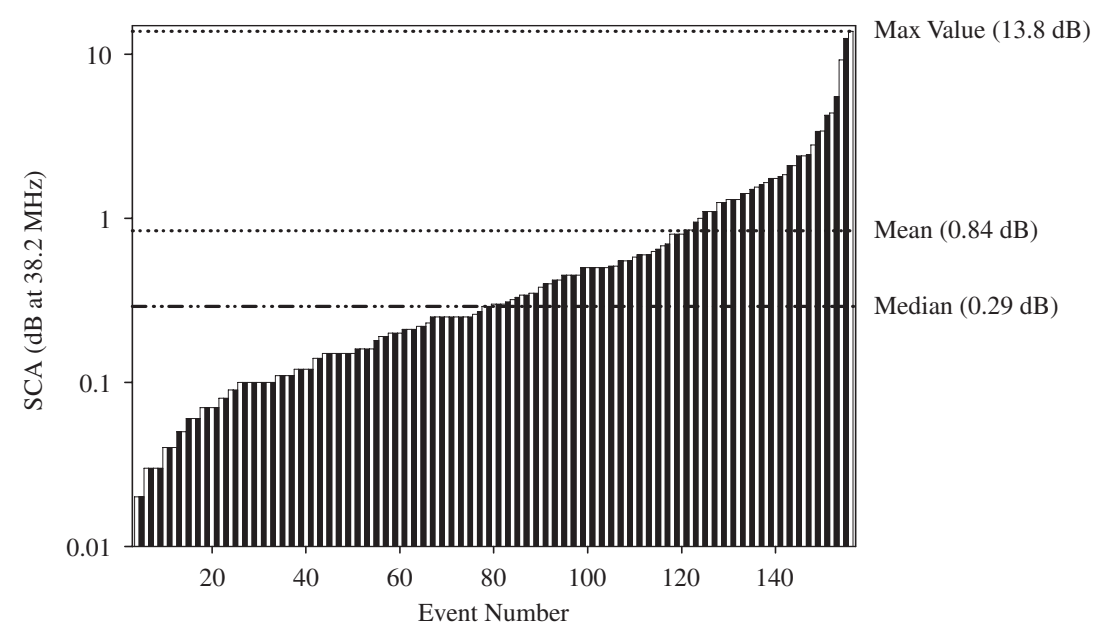

Fig. 4. Basic SCA statistics—sorted events.

Table 2

Statistics of riometer absorption during SSC events.

\begin{tabular}{lllll}
\hline Period & $\begin{array}{l}\text { No. events } \\
\text { (\% of } 175 \text { events) }\end{array}$ & $\begin{array}{l}\text { Mean SCA } \\
\text { dB }\end{array}$ & $\begin{array}{l}\text { Median SCA } \\
\mathrm{dB}\end{array}$ & $\begin{array}{l}\text { Standard deviation } \\
\mathrm{dB}\end{array}$ \\
\hline Day (6-18 MLT) & $104(59 \%)$ & 0.85 & 0.29 & 1.93 \\
Night (18-6 MLT) & $71(41 \%)$ & 0.83 & 0.26 & 1.57 \\
\hline
\end{tabular}

Over the 6-year period of measurements there is a wide variation in the amplitude of SCA measurements. However, as only approximately $20 \%$ of all the events exceed $1 \mathrm{~dB}$ the use of the median value is a better representation the full dataset.

\subsection{Influence of local time on SCA}

Table 2 gives a breakdown of SCA statistics divided into day events (6-18 MLT) and night events (18-6 MLT).

While the occurrence of SCA is slightly greater during the day there is no significant difference in the mean or median values of SCA between the two sectors. This illustrates that SCA occurs with similar characteristics during both the day and night. The response of the magnetosphere to abrupt solar wind enhancements is a global disturbance directly driven by the solar wind, and we believe that the response is typically not that of a substorm. This confirms similar findings by Zesta et al. (2000) and Boudouridis et al. (2004).

Fig. 5 presents a histogram indicating the number of SSC that occurred in each MLT hour over the 6-year period. The average number of SSC that occur in each hour is 7.3. Using a $\chi^{2}$ test the number of events occurring within each hour was evaluated against the expected value, assuming no change over time. The test was also repeated after grouping the data into eight 3-h periods and assuming no change in the expected value, in this case between adjacent 3-h time periods. Both tests were not significant at the $5 \%$ level indicting a random occurrence in the number of events that occurred both within each hour and within the 3-h groupings. This is in line with findings by Lee et al. (2004) that the solar wind pulse leads to a near simultaneous enhancement of the energetic flux at all MLT sectors at the geosynchronous orbit.

\subsection{Direction of $B_{z}$ and $S C A$}

Of the 175 SSC events selected for this study it was not possible to ascertain the direction of $B_{z}$ in 23 of the events due to data unavailability. The movement of $B_{z}$ during the shock was classified into four possible types as shown in Table 3. The absorption statistics for each of the 4 categories of $B_{z}$ direction described in Table 3 follows in Table 4.

The standard deviation in the North and South events is skewed significantly by the presence of very large outliers. Rather than remove the outliers, which are valid measurements, it was decided to leave them in so that the standard deviation can reflect the variance expected over a solar cycle. In $75 \%$ of the events, $B_{z}$ does not change direction during the shock and there is an almost equal split between north and south maintaining $B_{z}$.

The similarity in statistics between all four types of event indicates that the direction of $B_{z}$ has little impact on the typical values of SCA. This supports an assertion that Sudden Commencement Absorption is not caused by particles from the solar wind gaining access to the high latitude zone but rather from particles already captured in the magnetosphere. This confirms the same conclusion made by Paulikas and Blake (1970) in their paper examining proton flux both outside and inside the magnetosphere during the occurrence of SCC events.

SCA is therefore not caused by southward turning $B_{z}$ events as more than half of the selected SCA events occurred during northward $B_{z}$ movements, which in some cases continued even more strongly northward after the SSC event. The examination of these 152 events shows that similar precipitation events occur independently of the direction of $B_{z}$ immediately before or after the SSC event.

\subsection{The link between the solar wind, IMF and SCA}

Perreault and Akasofu (1978) studied how the solar wind energy is dissipated inside the magnetosphere during stormtime periods. They defined empirically an "energy coupling" function $(\varepsilon)$ as the fraction of the solar wind Poynting flux entering the magnetosphere. While $\varepsilon$ is proven to correlate well to stormtime periods it is compiled using hourly average values of variables and is not useful when studying short period (typically less than $15 \mathrm{~min}$ ) SSC events.

There are other forms of expression based on different combinations of solar wind parameters, which also correlate with substorm occurrence. There are many instances of substorms when $B_{z}$ is southward, when $B_{z}$ turns southward, but also when the IMF turns northward having been southward for a few hours before. In particular it has been shown that geomagnetic activity is principally controlled by the solar wind velocity and the IMF 


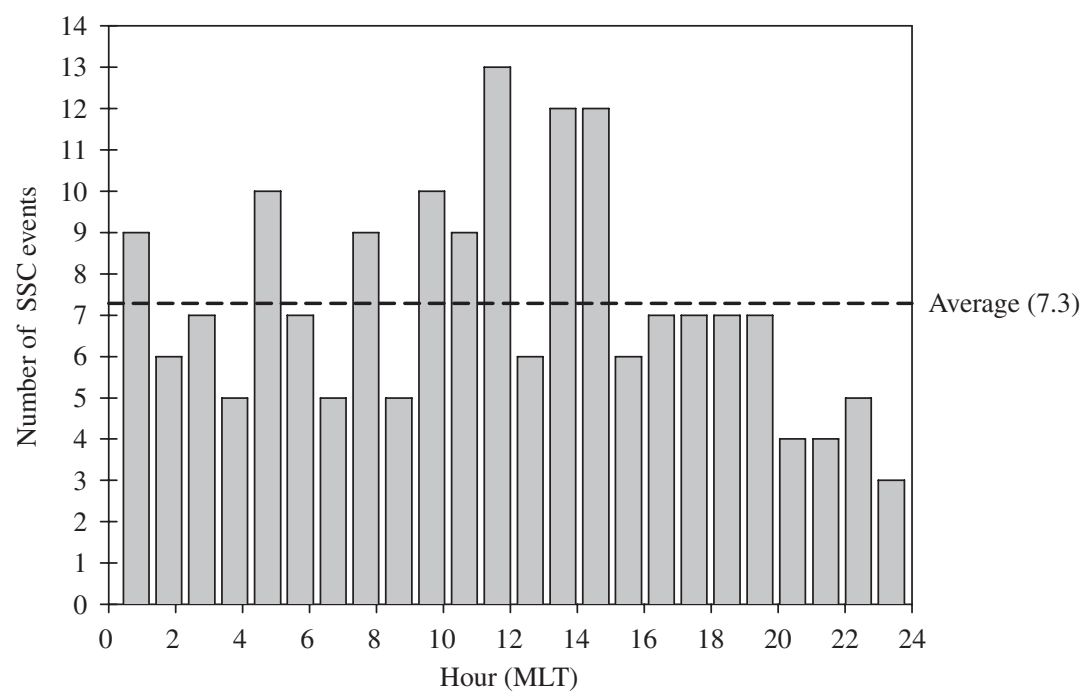

Fig. 5. Histogram of the number of SSC events that occur in each MLT hour.

Table 3

Breakdown of $B_{z}$ information into four categories according to direction of $B_{z}$ before and after the SSC event.

\begin{tabular}{ll}
\hline Designator & Description \\
\hline N2N & $\begin{array}{l}B_{z} \text { is positive before and after the shock, i.e. it remains } \\
\text { northward pointing }\end{array}$ \\
S2S & $\begin{array}{l}B_{z} \text { is negative before and after the shock, i.e. it remains } \\
\text { southward pointing }\end{array}$ \\
N2S & $\begin{array}{l}B_{z} \text { is positive before and changes to become negative after the shock } \\
\text { S2N }\end{array}$ \\
\hline
\end{tabular}

Table 4

Absorption Statistics for the four categories of $B_{z}$ movement.

\begin{tabular}{llllll}
\hline & \multicolumn{5}{l}{ Type of event (see Table 3 for description of type designator) } \\
\cline { 2 - 5 } & All events (dB) & North (dB) & South (dB) & N2S (dB) & S2N (dB) \\
\hline Mean & 0.81 & 0.8 & 0.73 & 0.56 & 0.54 \\
Median & 0.3 & 0.31 & 0.34 & 0.27 & 0.36 \\
Std. deviation & 1.77 & 1.9 & 1.1 & 0.64 & 0.53 \\
& & & & & \\
\% of total events & $100 \%(152)$ & $36 \%$ & $39 \%$ & $15 \%$ & $10 \%$ \\
\hline
\end{tabular}

field strength and direction (Burton et al., 1975; Maezawa, 1979). Other parameters such as density may play some role but are generally thought to be less important. With the exception of the occurrence of shock waves, the velocity and magnetic field strength are slowly changing parameters when compared with the magnetic field direction. Thus, while the strength of the IMF $(\Delta B)$ and the solar wind velocity $\left(V_{p}\right)$ may be very important parameters in controlling geomagnetic activity, it is the changes in field direction, which correlate well with geomagnetic events in the magnetosphere.

Fig. 6 examines the interdependency between the IMF and the solar wind. The top panel shows the correlation between the change in solar wind velocity and the IMF at the time of the shock. Although fairly weak, this is by far the best correlation as evidenced by the very weak correlation between particle density and IMF (middle panel) as well as between particle density and velocity (bottom panel). The correlation between velocity and IMF (Fig. 6 top panel) could be explained by remembering that the solar wind is magnetised plasma and that the faster, travelling shock wave will overtake the slower, preceding solar wind in front of the shock. This causes the magnetic flux to be compressed at the front of the shock with some proportionality to solar wind velocity.

As shown in Fig. 1, the velocity and magnetic field strength under go rapid change (as do other parameters such as density) during the shock and we need to test if there is any direct connection between any of these quickly changing parameters and the SCA measured. One method to do this is to find the best predictor of SCA based on one or more solar wind parameters in order to clarify the affect of solar wind and IMF shocks on SCA. In order to do this a substantial body of work was undertaken to correlate each parameter shown in Table 1, with the absolute, average and median values of SCA measured at the moment of SSC. The median value is a measure of central tendency that provides us with a description of the entire data set and is especially useful when data sets contain a few extremely high values that can skew the distribution, as is the case here. The median is less sensitive to extreme values than the mean and therefore, it is a very good summary statistic to use when the data contains outliers and is an appropriate measure when dealing with the highly variable ionosphere and magnetosphere. It is for similar reasons and also convenient that hourly median values are the standard output from HF propagation prediction programmes and using median values of SCA allows comparisons to be made.

Fig. 7 consists of four panels showing the median value of SCA compared against the step change in IMF $(\Delta B)$ (top panel), solar wind velocity $\left(\Delta V_{p}\right)$ (second panel), solar wind particle density $\left(\Delta N_{p}\right)$ (third panel) and solar wind ram velocity ( $\Delta$ Ram Pressure) (bottom panel). A first-order regression is applied to the last two scatter plots and a second-order regression is applied to the first two scatter plots. The choice of only a first-order regression for the last two plots was determined by the wide spread of values in the data. Fig. 7 demonstrates the strong correlation between solar wind velocity and SCA but also the even stronger correlation between the IMF and SCA.

By a wide margin, the strongest correlation was found between the median value of SCA measured and $\Delta B$, the step change in IMF magnitude that occurred during the shock. The fitted curve in the top panel of Fig. 7, with a correlation coefficient $\left(R^{2}\right)$ of 0.852 , is a second-order equation of the form:

$A_{m}=0.32-0.07 \Delta B+0.0077 \Delta B^{2}$

where $A_{m}$ is the median value of SCA expected and, $\Delta B$ is the change in IMF due to the shock. 

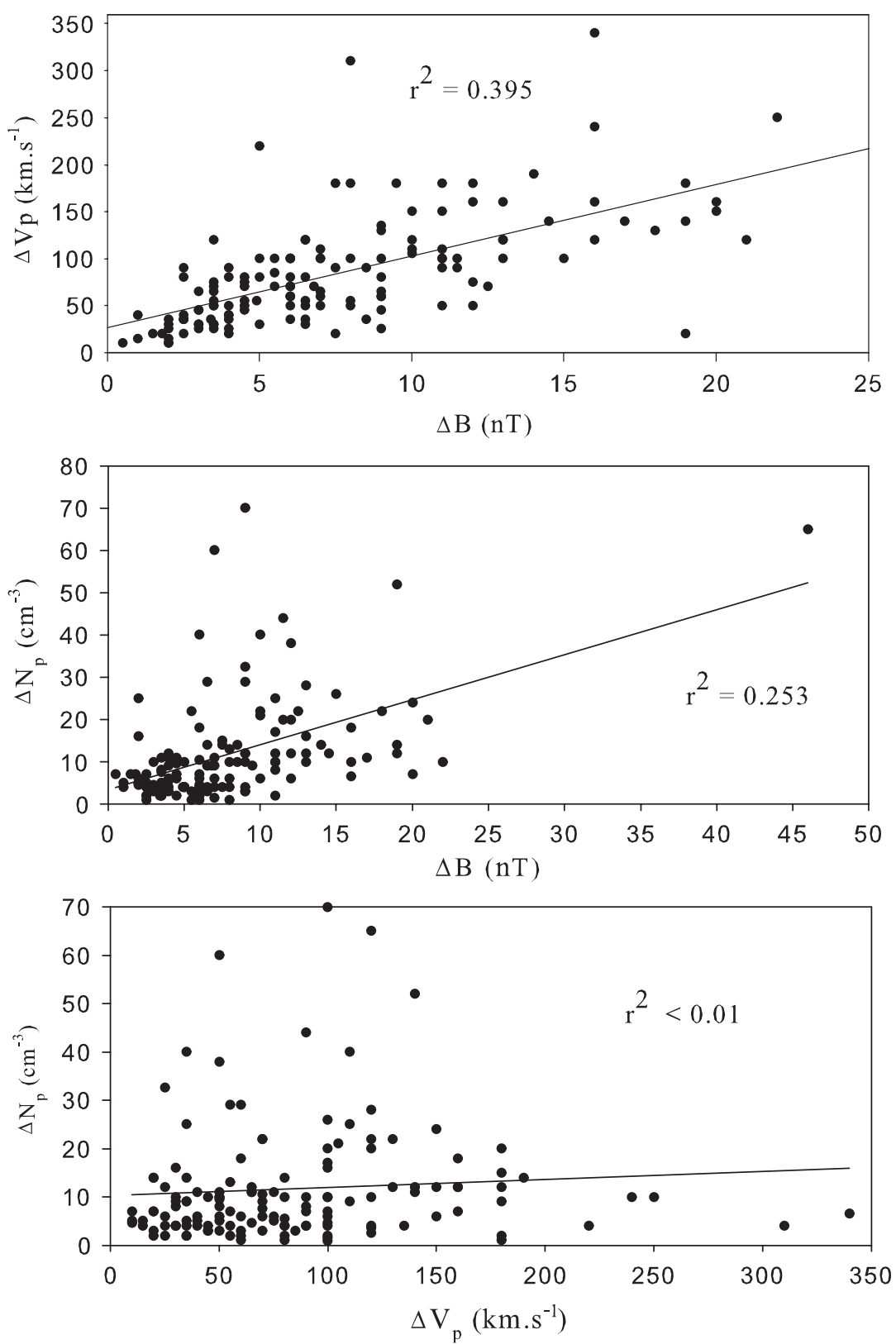

Fig. 6. Scatter plot and first-order regression of $\Delta V_{p}$ vs. $\Delta B$ (top panel), $\Delta N_{p}$ vs. $\Delta B$ (middle panel) and $\Delta N_{p}$ vs. $\Delta V_{p}$ (bottom panel).

The fit for $\triangle B$ against median SCA is very good at values of $\Delta B<25 \mathrm{nT}$, reducing somewhat at values of $\Delta B>25 \mathrm{nT}$. One explanation of this apparent phenomenon is that there may be some form of non-linear effect in the magnetosphere that only becomes evident as $\Delta B$ exceeds $25 \mathrm{nT}$. While this does bear further investigation less than $3 \%$ of SSC shocks in the data set generated a $\Delta B>25 \mathrm{nT}$, that is $\sim 5$ events in a 6-year period.

A further consideration in using $\Delta B$ as a predictor becomes evident when examining the differences in the $y$-axis of each panel in Fig. 7. When examining the solar wind velocity, particle density and ram pressure, the maximum median SCA does not exceed $2.5 \mathrm{~dB}$. Compare this to the top panel where SCA values in excess of $10 \mathrm{~dB}$ can be predicted when the IMF is used as the predictor. The reason for this anomaly is that the ACE SWEPAM data becomes unreliable in the presence of proton contamination and solar wind parameters are not reported (see for example NOAA, 2001a). These protons are invariably present following solar energetic particle events (see for example NOAA, 2001b), which are often responsible for the disturbance in the solar wind originally initiating the SSC event.

\section{Conclusion}

A detailed examination of sudden commencement absorption, the absorption that occurs simultaneously with storm sudden commencements has been undertaken in this paper. To the authors' knowledge this is the first time that a statistical analysis of the characteristics of sudden commencement absorption has been published. The results in this paper have a direct application to real-time and near-time ionospheric propagation predictions in respect of the prediction of the occurrence and expected amplitude of sudden commencement absorption.

By design the dataset spans more than half a solar cycle and this was used to determine if solar activity, using the relevant sunspot count as a proxy, influences the value of SCA. By 

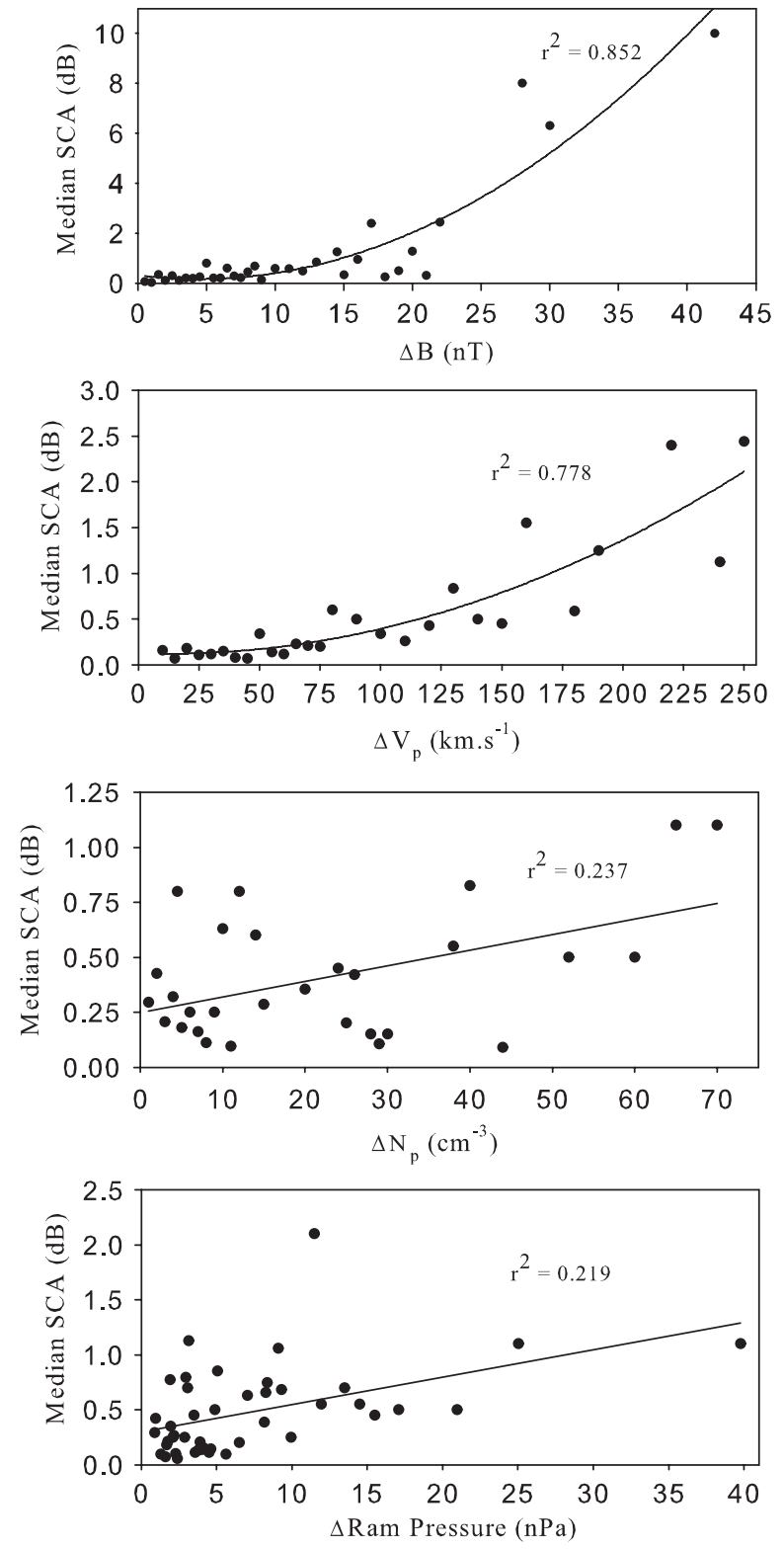

Fig. 7. Scatter plot and regression of median SCA vs. (from top to bottom) $\Delta B, \Delta V_{p}$, $\Delta N_{p}$ and $\Delta$ Ram Pressure.

evaluating the link between SCA and solar activity and the link between the change in IMF magnitude and solar activity it is concluded that in both cases there is no causal link, other than in the number of SSC events that occur. This last point is not unexpected as higher sunspot levels reflect the increase in the number of active regions on the Sun that are the source of shocks leading to SSC events.

Following the presentation of the basic database statistic, the influence of local time on SCA amplitude was investigated by dividing the dataset into day events (6-18 MLT) and night events (18-6 MLT). While the number of SSC events is slightly greater during the day there is no significant difference in the mean or median SCA values between the two sectors. This confirms that the immediate response of the magnetosphere to the shock is a global disturbance directly driven by the solar wind.

In considering all the possible combinations of how the direction of $B_{z}$ might change during the shock, the similarity between the statistics calculated for each of the four possible combination leads to the conclusion that the change in the direction of $B_{z}$ in what ever combination has very little impact on the value of SCA. This supports an assertion that SCA is caused by particles already captured in the magnetosphere. If it was the alternative option that solar wind carried particles were gaining direct access to high latitude zones than the change in solar wind-magnetosphere coupling, caused by changes in $B_{z}$ direction would be clearly evident, which is not the case.

In an attempt to model the expected SCA values after a shock has occurred, solar wind and IMF parameters were correlated in turn against the absolute, mean and median values of SCA. A strong correlation $\left(R^{2}=0.852\right)$ was found between the median value of SCA measured and the step change in IMF magnitude that occurred during the shock. In some ways this is not surprising as $\Delta B$ is fundamentally an indirect measure of the changes in solar wind proton velocity $\left(V_{p}\right)$. The fit is particularly good at $\Delta B$ values less than $25 \mathrm{nT}$, which accounts for $97 \%$ of the SSC events in the database. In addition due to proton contamination of the ACE SWEPAM instrument during large events, solar wind data are not reported, leaving the use of $\triangle B$ as the only reliable predictor of SCA during these times.

In summary the key findings in this paper are as follows:

i. There is no causal link between the amplitude of SCA and solar activity

ii. There is no causal link between the delta of IMF magnitude, caused by the passage of the shock wave past the ACE satellite, and solar activity.

These first two points are very relevant to radio engineers in that most propagation prediction programs only use a solar activity index to predict performance-the implication is that some other method is required-which this paper presents, namely an empirical relationship based on the change in IMF.

iii. SCA occurs with similar statistical characteristics during both the day and night.

iv. The direction of $B_{z}$ before and after the shock has little impact on the expected value of SCA.

The implication of these two points is that both of these variables can be ignored when predicting SCA.

$\mathrm{v}$. The change in the strength of the IMF is the best predictor of SCA for small to medium shocks and the only predictor of USA that can be used during large shocks.

\section{Acknowledgements}

This research is supported by the author's employer, the Commission for Communications Regulation (ComReg), Dublin, Ireland.

Acknowledgement of the following sources of data is made:

- The data originated from the Imaging Riometer for Ionospheric Studies (IRIS), operated by the Department of Communications Systems at Lancaster University (UK) in collaboration with the Sodankylä Geophysical Observatory, and funded by the Science and Technology Facilities Council (STFC).

- The ACE SWEPAM instrument team and the ACE Science Centre for providing the ACE data.

\section{References}

Boudouridis, A., Zesta, E., Lyons, L.R., Anderson, P.C., Lummerzheim, D., 2004 Magnetospheric reconnection driven by solar wind pressure fronts. Annales Geophysicae 22, 1367-1378.

Brown, R.R., Hartz, T.R., Landmark, B., Leinbach, H., Ortner, J., 1961. Large scale electron bombardment of the atmosphere at the sudden commencement of a geomagnetic storm. Journal Geophysics Research 66, 1035. 
Burlaga, L.F., Ogilvie, K.W., 1969. Causes of sudden commencements and sudden impulses. Journal Geophysical Research 74, 2815.

Burton, R.K., McPherron, R.L., Russel, C.T., 1975. An empirical relationship between interplanetary conditions and Dst. Journal of Geophysical Research 80, 4202.

Gail, W.B., Inan, U.S., Helliwell, R.A., Carpenter, D.L., 1990. Characteristics of waveparticle interactions during sudden commencements 1 . Ground-based observation. Journal of Geophysical Research 95 (A1), 119-137.

Gosling, J.T., Asbridge, J.R., Bame, S.J., Hundhausen, A.J., Strong, I.B., 1967. Discontinuities in the solar wind associated with sudden geomagnetic impulses and storm commencements. Journal of Geophysical Research 72 (13), 3357-3363.

Hargreaves, J.K., 1969. Auroral absorption of HF radio waves in the ionosphere: a review of results from the first decade of riometry. Proceedings of the IEEE 57, 1348-1373.

Hirshberg, J., Alksne, A., Colburn, D.S., Bame, S.J., Hundhausen, A.J., 1970 Observation of a solar flare induced interplanetary shock and helium-enriched driver gas. Journal of Geophysical Research 75 (1).

IAGA, Lists of SSC Events, ISGI Publications Office <www.cetp.ipsl.fr/lesdonne. htm $>$.

Kaufmann, R.L., Konradi, A., 1969. Explorer 12 magnetopause observations: largescale nonunifirm motion. Journal of Geophysical Research 74, 3609-3627.

Kavanagh, A.J., Honary, F., McCrea, I.W., Donovan, E., Woodfield, E.E., Manninen, J., Anderson, P.C., 2002. Substorm related changes in precipitation in the dayside auroral zone-a multi instrument case study. Annales Geophysicae 20, $1321-1334$.

Kikuchi, T., Yamagishi, H., 1989. Latitudinal features of cosmic noise absorption at the time of SSC-triggered substorm a observed with scanning beam riometer Proceedings of the NIPR Symposium on Upper Atmospheric Physics 2, 9-14.

Lee, D.-Y., Lyons, L.R., Yumoto, K., 2004. Sawtooth oscillations directly driven by solar wind dynamic pressure enhancements. Journal of Geophysical Research 109, A04202.

Leinbach, H., Schmidt, R.J., Brown, R.R., 1970. Conjugate observations of an electron precipitation event associated with the sudden commencement of a magnetic storm. Journal of Geophysical Research 75, 7099.

Little, C.G., Leinbach, H., 1959. The riometer-a device for the continuous measurements of ionospheric absorption. Proceedings of the Institute of Radio Engineers 37, 315-320.

Maezawa, K., 1979. Statistical study of the dependence of geomagnetic activity on solar wind parameters. In: Quantitative Modelling of Magnetospheric Processes (A80-15926 04-46). American Geophysical Union, Washington, DC, pp. 436-447.

NOAA, 2001a. Space Weather Highlights 24 September-30 September 2001, SWO PRF 1360, published on 2 October 2001.

NOAA, 2001b. Space Weather Highlights 5-11 November 2001, SWO PRF 1367, published on 13 November 2001.

Ogilvie, K.W., Burlage, L.F., Wilkerson, T.D., 1968. Plasma observations on Explore 34. Journal of Geophysical Research 73, 6809.

Ortner, J., Hultqvist, B., Brown, R.R., Hartz, T.R., Holt, O., Landmark, B., Hook, L. Leinbach, H., 1962. Cosmic noise absorption accompanying geomagnetic storm sudden commencements. Journal Geophysics Research 67, 4169.
Osepian, A., Kirkwood, S., 2004. Cosmic radio noise absorption bursts caused by solar wind shocks. Annales Geophysicae 22, 2973-2987.

Paulikas, G.A., Blake, J.B., 1970. Effects of SC on solar protons at the synchronous orbit. Journal of Geophysical Research, Space Physics 75 (4).

Perreault, P., Akasofu, S.-I., 1978. A study of geomagnetic storms. Geophysical Journal of the Royal Astronomical Society 54 (3), 547-573.

Perona, G.E., 1972. Theory on the precipitation of magnetospheric electrons at the time of sudden commencements. Journal of Geophysical Research 77, 101-111.

Ranta, A., Ranta, H., 1990. Storm sudden commencements observed in ionospheric absorption. Planetary Space Science 38 (3), 365-372.

Rastogi, R.G., Pathan, B.M., Rao, D.R.K., Sastry, T.S., Sastri, J.H., 2001. On latitudinal profile of Storm Sudden Commencement in $\mathrm{H}, \mathrm{Y}$ and $\mathrm{Z}$ at Indian Geomagnetic Observatory chain. Earth Planets Space 53, 121-127.

Russell, C.T., Ginskey, M., Petrinec, S.M., 1994. Sudden impulses at low-latitude stations: steady state response for northward interplanetary magnetic field. Journal of Geophysical Research 99 (A1), 253-262.

SEC 07, 2007. Explanation of Real-time Solar Wind Data Dials. NOAA National Weather Service Space Environment Center 〈http://www.sec.noaa.gov/SWN/ sw_dials.html $>$.

Stone, E.C., Frandsen, A.M., Mewaldt, R.A., Christian, E.R., Margolies, D., Ormes, J.F., Snow, F., 1998. The advanced composition explorer. Space Science Reviews 86 (1/4), 1-22.

Takeuchi, T., Russell, C.T., Araki, T., 2002. Effect of the orientation on interplanetary shock on the geomagnetic sudden commencement. Journal of Geophysical Research 107 (A12), 1423.

Tamao, T., 1975. Unsteady interactions of solar wind disturbances with the magnetosphere. Journal of Geophysical Research 80 (31), 4230-4236.

Tamao, T., 1964. The structure of three-dimensional hydromagnetic waves in a uniform cold plasma. Journal of geomagnetism and geoelectricity 16, 89 .

Tsurutani, B.T., Gonzalez, W.D., Gonzalez, A.L.C., Tang, F., Okada, J.K., 1995. Interplanetary origin of geomagnetic activity in the declining phase of the solar cycle. Journal of Geophysical Research 100 (A11), 21717-21734.

Wilken, B., Baker, D.N., Higbie, P.R., Fritz, T.A., Olsen, W.P., Pfitzer, K.A., 1986. Magentospheric configuration and energetic particle effects associated with SSC: a case study of the CDAW 6 event on March 22, 1979. Journal of Geophysical Research 91 (A2), 1459-1473.

Wilken, B., Goertz, C.K., Baker, D.N., Higbie, P.R., Fritz, T.A., 1982. The SSC on July 29, 1977 and its propagation within the magnetosphere. Journal of Geophysical Research 87 (A8), 5901-5910.

Wilson, A., Stoker, P.H., 2002. Imaging riometer observations on energetic electron precipitation at SANAE IV, Antarctica. Journal of Geophysical Research 107 (A10), 1268.

Wilson, C.R., Sugiura, M., 1961. Hydromagnetic interpretation of sudden commencements of magnetic storms. Journal Geophysical Research 66, 4097.

Zesta, E., Singer, H.J., Lummerzheim, D., Russell, C.T., Lyons, L.R., Brittnacher, M.J., 2000. The Effect of the January 10,1997, Pressure Pulse on the Magnetosphere-Ionosphere Current System. In: Ohtani, S., Fujii, R., Hesse, M., Lysak, R.L. (Eds.), Magnetospheric Current Systems. Geophysical Monograph 118. American Geophysical Union, Washington, DC, p. 217. 